\title{
The Fine Structure of Sporangia of Phytophthora erythroseptica Pethyb.
}

\author{
By J. A. CHAPMAN AND RADMILA VUJIČĆC \\ The Biophysics Unit, Rheumatism Research Centre, and the Department \\ of Cryptogamic Botany, University of Manchester, England
}

(Received 6 July 1965)

SUMMARY

Young non-germinating sporangia of Phytophthora erythroseptica contain nuclei and cytoplasmic organelles, similar in appearance to those in other fungi, and a conspicuous central and other vacuoles. The sporangial wall consists of an outer homogeneous layer and an inner vesicular layer, prominent in the apical region. Peripheral cytoplasmic vacuoles are frequent, particularly where the vesicular layer is well developed. In old sporangia, which lose the ability to germinate indirectly (i.e. to produce zoospores), there is no vesicular layer and there is a change in the nature of the storage material of the vacuoles. When young sporangia are stimulated to indirect germination by low-temperature treatment the central storage vacuole disappears and there is a marked elongation of mitochondrial cristae, consistent with an increased rate of respiration. The sporangial wall becomes three-layered with the development of an inner homogeneous layer which separates the plasma membrane from an increasingly prominent vesicular layer. In the region of the papilla the vesicular layer shows a striking increase in thickness; it is suggested that this layer and the inner homogeneous layer play an important part in zoospore discharge.

\section{INTRODUCTION}

Despite extensive studies of the morphology and physiology of sporangial formation and germination in Phytophthora and other fungi (review by Waterhouse, 1962) little is known of the fine structure of the sporangia of these organisms. Blondel \& Turian (1960) described the ultrastructure of gametangia of Allomyces but the present authors are not aware of other studies of sporangial fine structure in fungi. As in other species of the genus Phytophthora, sporangia of $\boldsymbol{P}$. erythroseptica may germinate either directly by germ tubes or indirectly by liberation of zoospores (Pethybridge, 1914; Blackwell, 1949). The age of a sporangium is an important factor in determining which of these two modes of germination will be adopted; old sporangia lose the ability to germinate indirectly (Blackwell, 1949). In an attempt to correlate these physiological changes with changes in small-scale morphology our description will include accounts of fine structure in ageing sporangia and in indirectly germinating sporangia, i.e. during zoospore formation.

\section{METHODS}

The organism examined in this study was Phytophthora erythroseptica Pethyb., the isolate used being one of those maintained in the collection of the Department of Cryptogamic Botany in the University of Manchester. The culture of P erythro- 
septica was incubated on pea broth (Leonian, 1934) at $22^{\circ}$ for 7 days; the mycelial mats were then washed in sterile distilled water and transferred to Petri's solution to induce sporulation (Vujičić \& Colhoun, 1966). Sporangia, together with small tufts of mycelium, were harvested from these mycelial mats 4 days after transfer (for young sporangia) or 8-10 days after transfer (for old sporangia). Specimens were fixed in $1 \%(\mathrm{w} / \mathrm{v})$ osmium tetroxide in veronal +acetate buffer $(\mathrm{pH} \mathrm{7 \cdot 3}$; Palade, 1952) or in $2 \%(\mathrm{w} / \mathrm{v})$ potassium permanganate in veronal + acetate buffer (pH 7.2; Luft, 1956). Fixation was carried out at $0-4^{\circ}$ for $2 \mathrm{hr}$ in $\mathrm{OsO}_{4}$ or for $1 \mathrm{hr}$ in $\mathrm{KMnO}_{4}$.

After washing in tap water the specimens were dehydrated in ethanol and embedded in Araldite epoxy resin (Glauert \& Glauert, 1958). The polymerized blocks were trimmed so that the face of each block contained one sporangium. Trimming of blocks was facilitated by special methods which will be described separately (Chapman, J. A. to be published 1966). Sections 600-800 \& in thickness were cut on a Huxley ultra-microtome with a glass knife. The sections were examined and photographed at magnifications ranging from $\times 1000$ to $\times 20,000$ in a Siemens Elmiskop I electron microscope operating at $80 \mathrm{kV}$ and with double condenser illumination. Exposures were made on Ilford lantern contrasty plates.

The following specimens were examined: (a) young sporangia from 4-day cultures (10 sporangia examined); (b) old non-germinating sporangia from 8- to 10 day cultures ( 6 sporangia); (c) young sporangia stimulated by low-temperature treatment to germinate indirectly to produce zoospores (5 sporangia). In this treatment $(c)$ pieces of sporulating mycelia, previously incubated at $22^{\circ}$ for 4 days, were transferred to hanging-drop cultures and maintained at $13^{\circ}$ for $1.5 \mathrm{hr}$ and then brought to $22^{\circ}$ for $10 \mathrm{~min}$. before fixation. In control specimens, left unfixed, this treatment brought about zoospore discharge from 70 to $80 \%$ of the sporangia within $15 \mathrm{~min}$. of raising the temperature (Vujičic \& Colhoun, 1966). Although fixed specimens were all taken at the same time-point (10 min. after raising the temperature) they contained sporangia at various stages of indirect germination so that ultrastructural changes occurring during the advancement of indirect germination could be inferred.

\section{RESULTS}

\section{The structure of the young non-germinating sporangium}

The appearance of a typical sporangium of Phytophthora erythroseptica at a low electron optical magnification is shown in Pl. 1, fig. 1. A large vacuole, irregular in shape and with a maximum diameter of approximately $5 \mu$, occupies a central position and smaller vacuoles are abundant throughout the cytoplasm. Several nuclei can be seen. The sporangium is surrounded by an electron-transparent wall, and the plug connecting the sporangium to a hypha is shown.

Higher magnifications revealed that the structure of the nuclei, endoplasmic reticulum, mitochondria and other cytoplasmic inclusions resembled closely that described for other fungi (Blondel \& Turian, 1960; Zalokar, 1961; Hawker \& Abbott, 1963; Moore \& McAlear, $1963 a, b$ ). The nuclei are relatively large bodies, $1.5-3 \mu$ in diameter, roughly ellipsoidal in shape but with minor irregularities in outline. In permanganate-fixed material they possess a homogeneous finely granular appearance (Pl. 1, fig. 2). The nuclear envelope comprises a double membrane 
traversed by numerous pores. Apparent continuity between the nuclear membrane and membranous organelles in the cytoplasm was occasionally noted.

Elongated cisternae of the endoplasmic reticulum occur widely in the cytoplasm (Pl. 1, fig. 2; Pl. 2, fig. 3). Ribosomal particles, free or attached to cisternal membranes, cannot be detected in permanganate-fixed material because of the failure of permanganate to preserve ribonucleoprotein (Luft, 1956). After osmium fixation ribosomes, occurring as electron-opaque particles $150 \AA$ in diameter, are abundantly distributed throughout much of the sporangial cytoplasm (Pl. 3, fig. 4). The identification of these particles as ribosomes is supported by the work of Blondel \& Turian (1960), who showed that similar particles were responsible for basophilia in hyphae and gametangia of the fungus Allomyces. These authors found that ribosomes were freely dispersed in the cytoplasm, and showed no preferential attachment to membranes of the endoplasmic reticulum; our results suggest that a similar situation exists in sporangia of Phytophthora erythroseptica.

Golgi dictyosomes were sometimes noted, usually in proximity to nuclei (Pl. 1, fig. 2). These took the characteristic form of stacks of close-packed flattened cisternae associated with smaller vesicles apparently pinched off from the cisternal margins; they closely resemble the Golgi dictyosomes found in higher plants and in other fungi (Moore \& McAlear, 1963 a). Similar Golgi dictyosomes, also adjacent to nuclei, were observed in older sporangia (Pl. 4, fig. 8).

Mitochondria of varied shape and size occur in abundance in the sporangial cytoplasm ( $\mathrm{Pl}$. 2, fig. 3). The inner of the two limiting mitochondrial membranes is infolded into the mitochondrial matrix to form the mitochondrial cristae. In young non-germinating sporangia these cristae are short and stumpy.

In addition to the large central vacuole (shown in part in $\mathrm{Pl} .3$, fig. 6), the young sporangium contains numbers of smaller storage vacuoles, also irregular in outline and with electron-transparent contents. Yamamoto \& Tanino (1961) showed that sporangia of Phytophthora infestans were rich in glycogen and it is probable that this glycogen is located in the central and surrounding vacuoles; glycogen does not reduce osmium tetroxide nor (under normal conditions) permanganate (Revel, 1964) and the appearance of the vacuolar contents of $\boldsymbol{P}$. erythroseptica (as in $\mathrm{Pl} .3$, fig. 6) is consistent with the presence of glycogen in the unstained areas (Zalokar, 1961).

Lipid inclusions occur in the form of small electron-transparent bodies of irregular shape with an intensely electron-opaque periphery (after osmium or permanganate fixation). The over-all diameter of these inclusions ranges from $0 \cdot 3$ to $0.8 \mu$ (Pl. 3, fig. 4; Pl. 4, fig. 7). In osmium-fixed specimens some inclusions possess a fine lamellar structure with a periodicity of $60-70 \AA$ (Pl. 3, fig. 4) suggesting that the contained material is phospholipid.

The peripheral regions of the sporangial cytoplasm contain rounded vacuoles about $\mathbf{0 \cdot 3} \mu$ in diameter and limited by a single membrane (Pl. 1, fig. 2; Pl. 2, fig. 3 ). These vacuoles, henceforth described as 'peripheral vacuoles', occasionally show an invagination of the limiting membrane penetrating almost to the centre of the vacuole (centre and bottom of $\mathrm{Pl}$. 2, fig. 3). The finely granular contents possess an electron opacity comparable to that of the surrounding cytoplasm and in some instances the contents may be resolved as small vesicles up to $250 \AA$ across (lower right of $\mathrm{Pl}$. 2, fig. 3). 
Particular interest attaches to the sporangial wall since this complex structure shows marked changes on ageing or during the course of indirect germination. The wall of a young sporangium (from a 4-day culture) consists of two layers outside the plasma membrane (Pl. 1, fig. 2; Pl. 2, fig. 3). The outer layer is structureless and (apart from a thin region bordering the sporangial surface) relatively electron transparent after both fixatives. It has a thickness of 2000-3000 $\AA$. This layer would seem to be the one which gives a cellulose reaction when sporangia are treated with sulphuric acid and iodine in potassium iodide and examined by light microscopy (Pethybridge, 1914). The inner layer is variable in thickness and less electron transparent than the outer layer; its most characteristic feature is the presence of small vesicles, up to $500 \AA$ in diameter and often occurring in groups. The vesiculated nature of this layer is particularly apparent in the wall surrounding the apical region of the sporangium (Pl. 2, fig. 3); in other regions the vesicular elements are more sparsely distributed (Pl. 1, fig. 2). In young sporangia a welldeveloped vesicular layer is associated with an abundance of peripheral vacuoles in the neighbouring cytoplasm (compare figs. 2 and 3) suggesting that these vacuoles may play an active part in vesicle formation. In such regions the plasma membrane is convoluted with numerous cytoplasmic extensions protruding into the vesicular layer (P1. 2, fig. 3).

Under the light microscope the papilla, which is involved in the liberation of zoospores in indirect germination, appears as a mucilaginous thickening of the apical wall (Blackwell, 1949). In young non-germinating sporangia the papilla is inconspicuous and this may account for our failure to observe the papillar region in ultra-thin sections of such sporangia. Sections of papillae in older sporangia and in sporangia stimulated to indirect germination were readily obtained.

The plug connecting the hypha to the base of the sporangium serves to separate the hyphal contents from those of the sporangium. It consists of a greatly thickened region of wall interspersed with aggregates of electron-opaque material (Pl. 3, fig. 5). A distinct boundary exists, however, between the outer wall and the plug material. The appearance of this material suggests that the plug is formed in layers, possibly by intussusception of new layers between old ones. During its formation the plug always bulges into the sporangium but it may also bulge to a lesser extent into the hypha.

\section{The structure of old non-germinating sporangia}

The most conspicuous cytoplasmic change taking place on ageing occurs in the central vacuole, in which the contained material becomes uniformly electron transparent (Pl. 4, fig. 7). This is consistent with the light optical evidence that the storage material of the sporangium is transformed into some other reserve material (Blackwell, 1949). Lipid inclusions tend to be more numerous in old sporangia.

The sporangial wall consists of a single layer only (Pl. 4, fig. 8). The vesicular layer was absent and the outer structureless electron-transparent layer, now decreased in thickness to $1500-2000 \AA$, is directly apposed to the plasma membrane.

The papilla in an old sporangium appears as a homogeneous layer, finely granular after osmium fixation; it abuts directly on to the plasma membrane (Pl. 4, fig. 9). The plug has the same appearance in young and old sporangia ( $\mathrm{Pl}$. 3, fig. 5). 


\section{The structure of the young sporangium stimulated to germinate indirectly}

Sudden exposure to a temperature of $13^{\circ}$ for $1.5 \mathrm{hr}$ followed by $10-15 \mathrm{~min}$. at $22^{\circ}$ (the stimulus for indirect germination) is sufficient to bring about several important structural changes. The central glycogen vacuole disappears and the cytoplasm contains a decreased number of smaller vacuoles which are now irregular in outline and possess structureless electron-transparent contents. Few peripheral vacuoles are recognizable. Mitochondria are enlarged and it is particularly noticeable that the cristae are elongated and penetrate deeply into the mitochondrial matrix (compare Pl. 5, figs. 11 and 12, with Pl. 2, fig. 3).

The sporangial wall shows a marked increase in complexity during the process of indirect germination. The outer structureless layer is unaltered, but the inner vesicular layer widens and, as germination advances, vesicular elements increase considerably in number and pack together to form a discrete, heterogeneous layer (Pl. 5, fig. 11). At this stage, moreover, a third layer is formed, separating the vesicular layer from the plasma membrane. This third and inner layer resembles the outermost layer of the wall in its low electron opacity and apparent absence of structure. It is conspicuous only in the walls of chilled sporangia, particularly when the changes are well advanced; there may, however, be indications of the beginning of a third layer in the apical wall of young non-germinating sporangia (Pl. 2, fig. 3).

The development of the papilla is even more striking. In the early stages of indirect germination the papilla is largely homogeneous and consists predominantly of a thickened outer structureless layer, although the vesicular layer and the innermost structureless layer are clearly detectable (Pl. 5, fig. 10). At a later stage the papilla presents a very different picture, with the vesicular layer now occupying the bulk of the central space (Pl. 5, fig. 12). The layer embodies a heterogeneous assortment of vesicles, some up to $1 \mu$ in diameter and mostly containing moderately electron-opaque material; some less clearly defined vesicles of uniform size (0.5 $\mu$ ) lie adjacent to the innermost cell wall and contain homogeneous material of lower electron opacity. The outer structureless layer is displaced outwards by the enlarged vesicular zone and a prominent bulge forms at the apex of the sporangium.

The elements comprising the plug remain unchanged during the process of indirect germination and the plug is not penetrated by the vesicular elements of the neighbouring wall.

\section{DISCUSSION}

During the process of ageing a sporangium of Phytophthora erythroseptica undergoes a series of irreversible changes which result in the loss of ability to germinate indirectly by the production of zoospores. Our electron microscope observations show that ageing is accompanied by a change in the appearance of the contents of the food vacuoles and by the disappearance of the vesicular layer in the wall. These changes suggest that the original food storage material (probably glycogen) and the vesicular layer of the wall both play essential roles in indirect germination. Two distinct processes are at work during indirect germination. The formation of zoospores involves the differentiation and cleavage of the sporangial cytoplasm. 
Secondly, the sporangial wall must open in the region of the papilla to permit the discharge of zoospores. The occasional release of sporangial contents before cytoplasmic differentiation is complete (Pethybridge, 1914; Waterhouse, 1962; Vujičić $\&$ Colhoun, 1966) indicates that the two mechanisms can operate independently even though they are normally stimulated by the same external conditions.

It is to be expected that the process of cytoplasmic differentiation will require an adequate source of energy and Yamamoto \& Tanino (1961) showed that the glycogen content decreased and respiration increased during zoospore formation in sporangia of Phytophthora infestans. The results of the present study show that these physiological changes in $\boldsymbol{P}$. erythroseptica can be correlated with corresponding changes in ultrastructure. Thus the disappearance of the large central vacuole together with the decrease in number and the change in appearance of the smaller vacuoles in chilled sporangia are consistent with a decrease in glycogen content. It is probable that the glycogen is converted into glucose and utilized as an energy source. The increase in respiration rate noted by Yamamoto \& Tanino can be related to the changes in mitochondrial structure which occur after chilling. The short stumpy cristae in mitochondria of young non-germinating sporangia become elongated during indirect germination and penetrate deeply into the mitochondrial matrix; some increase in mitochondrial size is also apparent. Simon \& Chapman (1961) noted that a rise in succinoxidase activity in developing Arum spadix cells was accompanied by a similar increase in the length of mitochondrial microvilli, while Hawker \& Abbott (1963) noted that the number and length of mitochondrial cristae in vegetative hyphae of Rhizopus increased with hyphal age.

Discharge of the sporangial contents occurs on dissolution or rupture of the papilla. By this stage the sporangial wall of Phytophthora erythroseptica consists of three distinct layers: the outer wall (probably cellulose), the prominent vesicular layer and the innermost homogeneous layer. The striking development of the vesicular layer during indirect germination, particularly in the region of the papilla, and the emergence of the third layer separating the vesicular layer from the plasma membrane, are in marked contrast to the unaltered appearance of the outer sporangial wall. These observations provide clear evidence that the two inner layers are implicated in the discharge process and it may be postulated that the vesicles contain enzymes responsible for the ultimate degradation of papillar components.

Zoospores of Phytophthora may be liberated in various ways. The usual mechanism is by the discharge of zoospores as single mature motile organisms (Blackwell, 1949). In several species, however, for example in Phytophthora cryptogea (Pethybridge \& Lafferty, 1919), P. cactorum (Wormald, 1919) and P. colocasiae (Blackwell $\&$ Waterhouse, 1930), zoospores may be expelled as a mass surrounded by a thin evanescent vesicle which remains attached to the mouth of the sporangium; in not more than a few seconds the zoospores break through the vesicle and swim away. In $\boldsymbol{P}$. cryptogea the evanescent vesicle may be so tough that the zoospores must puncture a hole through which they escape singly (Blackwell, 1949). In the case of $\boldsymbol{P}$. erythroseptica however the evanescent vesicle is apparently so delicate and transitory that it has only rarely been described (Pethybridge, 1914; Vujičić, 1963) and no trace of the vesicle remains after the dispersion of the zoospores. Light microscopy indicates that the evanescent vesicle is derived from the hyaline material 
which comprises the papilla of the indirectly germinating sporangium (Pethybridge, 1914; Pethybridge \& Lafferty, 1919; Wormald, 1919; Blackwell, 1949); the papilla has been described by Blackwell as a localized mucilaginous area of the inner sporangial wall which readily imbibed water and dissolved to allow emission of zoospores, sometimes giving rise to the evanescent vesicle during the process of solution. On the evidence provided by the present work it seems probable that this mucilaginous zone is the vesicular layer of the sporangial wall and that the evanescent vesicle is in some way derived from this layer.

The authors are indebted to Professor J. Colhoun of the Department of Cryptogamic Botany, Manchester University, for his advice and encouragement throughout the investigation and to the Nuffield Foundation and the Agricultural Research Council for grants for the purchase of equipment.

\section{REFERENCES}

Blackwell, E. M. (1949). Terminology in Phytophthora. Mycol. Pap. no. 30.

BlackWell, E. M. \& Waterhouse, G. M. (1930). Spores and spore germination in the genus Phytophthora. Trans. Br. mycol. Soc. 15, 294, 320.

Blondel, B. \& Turian, G. (1960). Relation between basophilia and fine structure of cytoplasm in the fungus Allomyces macrogynus Em. J. biophys. biochem. Cytol. 7, 127.

Glauert, A. M. \& Glauert, R. H. (1958). Araldite as an embedding medium for electron microscopy. J. biophys. biochem. Cytol. 4, 191.

Hawker, L. E. \& ABbott, P. McV. (1963). Fine structure of vegetative hyphae of Rhizopus. J. gen. Microbiol. 30, 401.

Leonian, L. H. (1934). Identification of Phytophthora species. Bull. W. Va Univ. agric. Exp. Stn. no. 262, p. 32.

LuFT, J. H. (1956). Permanganate-a new fixative for electron microscopy. J. biophys. biochem. Cytol. $2,799$.

Moore, R. T. \& McAlear, J. H. (1963a). Fine structure of mycota. 4. The occurrence of the Golgi dictyosome in the fungus Neobulgaria pura (Fr.) Petrak. J. Cell Biol. 16, 131.

Moore, R. T. \& McAlcar, J. H. (1963b). Fine structure of mycota. 9. Fungal mitochondria. J. Ultrastr. Res. 8, 144.

Palade, G. E. (1952). A study of fixation for electron microscopy. J. exp. Med. 95, 285.

Pethybridge, G. H. (1914). Further observations on Phytophthora erythroseptica Pethyb., and on the disease produced by it in the potato plant. Scient. Proc. R. Dubl. Soc. 14 (N.S.), 179.

Pethybridge, G. H. \& Lafferty, H. A. (1919). A disease of tomato and other plants caused by a new species of Phytophthora. Scient. Proc. R. Dubl. Soc. 15 (N.S.), 487.

Revel, J. P. (1964). Electron microscopy of glycogen. J. Histochem. Cytochem. 12, 104.

Simon, E. W. \& Chapman, J. A. (1961). The development of mitochondria in Arum spadix. J. exp. Bot. 12, 414.

VuJıčıć, R. (1963). Asexual reproduction in Phytophthora erythroseptica Pethyb. Ph.D. dissertation, Manchester University.

Vusıčıć, R. \& Colнoun, J. (1966). Sporangial production by Phytophthora erythroseptica Pethyb. Trans. Brit. mycol. Soc. (In the press)

Waterhouse, G. M. (1962). The zoospore. Trans. Br. mycol. Soc. 45, 1.

Wormald, H. (1919). A Phytophthora rot of pears and apples. Ann. appl. Biol. 6, 89.

Yамamoto, M. \& Tanino, J. (1961). Physiological studies on the formation and germination of sporangia of Phytophthora infestans (Mont.) DeBary. Forschn Geb. PfiKrankh., Kyoto, 7, 7.

ZaloKar, M. (1961). Electron microscopy of centrifuged hyphae of Neurospora. J. biophys. biochem. Cytol. 9, 609. 


\section{EXPLANATION OF PLATES}

\begin{tabular}{llll}
\multicolumn{4}{c}{ Abbreviations used } \\
ev & central vacuole & $n$ & nucleus \\
er & endoplasmic reticulum & $n m$ & nuclear membrane \\
$g$ & Golgi dictyosome & $n p$ & nuclear pore \\
hy & hypha & $p$ & plug \\
$l a m$ & lamellar inclusion & $p a$ & papilla \\
$l i p$ & lipid inclusion & $p m$ & plasma membrane \\
$m$ & mitochondrion & $p v$ & peripheral vacuole \\
$m c$ & mitochondrial cristae & $r i b$ & ribosomes \\
& $w_{1}$ outer sporangial wall (homogeneous) \\
& $w_{2}$ vesicular sporangial wall (heterogeneous) \\
& $w_{3}$ inner sporangial wall (homogeneous)
\end{tabular}

\section{Plate 1}

Fig. 1. Low magnification electron micrograph of a young sporangium of Phytophthora erythroseptica showing the central vacuole $(c v)$ and the plug $(p)$ connecting the sporangium to a hypha. Nuclei $(n)$ are scattered in the cytoplasm. (Fixative $\mathrm{OsO}_{4} ; \times 2500$.)

Fig. 2. Wall and cytoplasm of a young sporangium (from a 4-day-old culture). The sporangial wall consists of a thick homogeneous outer layer $\left(w_{1}\right)$ and an inner vesicular layer $\left(w_{2}\right)$ bordering the plasma membrane $(p m)$. The nucleus $(n)$ is enveloped by a double membrane $(n m)$ penetrated by pores $(n p)$. Flattened cisternae and associated vesicles of a Golgi dictyosome ( $g$ ), endoplasmic reticulum (er) and peripheral vacuoles $(p v)$ are shown. (Fixative $\mathrm{KMnO}_{4} ; \times 80,000$.)

\section{Plate 2}

Fig. 3. The apical region of a young sporangium. The vesiculated layer $\left(w_{2}\right)$ of the sporangial wall is well developed and the underlying plasma membrane $(p m)$ shows numerous convolutions. Peripheral vacuoles $(p v)$ are conspicuous in the outer regions of the cytoplasm; their finely granular contents are at places resolvable as small vesicles (arrows). Mitochondria $(m)$ possess short stumpy cristae $(m c)$ and extensive areas of clear matrix; elongated cisternae of the endoplasmic reticulum $(e r)$ occur in the vicinity of the nucleus $(n)$. (Fixative $\mathrm{KMnO}_{4} ; \times 60,000$.)

\section{Plate 3}

Fig. 4. Lipid inclusions (lip) and inclusions with regions showing a periodic lamellar structure (lam) occur in the sporangial cytoplasm. Osmiophilic ribosomal particles (rib) are abundant. 8-day-old culture. (Fixative $\mathrm{OsO}_{4} ; \times 140,000$.)

Fig. 5. The plug $(p)$ separating the sporangium from the hypha $(h y)$ in a young (4-day) specimen. (Fixative $\mathrm{OsO}_{4} ; \times 20,000$.)

Fig. 6. Part of the central vacuole $(c v)$ in a young (4-day) sporangium. (Fixative $\mathrm{KMnO}_{4} ; \times 90,000$.)

Plate 4

Fig. 7. Part of the central vacuole (cv) and adjacent cytoplasm in an old (10-day) sporangium. Mitochondria $(m)$ and a lipid inclusion $(l i p)$ are shown. (Fixative $\mathrm{KMnO}_{4} ; \times 35,000$.)

Fig. 8. Wall and cytoplasm of an old (10-day) sporangium. The wall consists only of the outer homogeneous layer $\left(w_{1}\right)$; the inner vesiculated layer is absent. A nucleus $(n)$ and nearby Golgi dictyosome (g) are shown. (Fixative $\mathrm{KMnO}_{4} ; \times 40,000$.)

Fig. 9. Part of the papillar region in an old (8-day) sporangium. The papillae $(p a)$ appear as a thick finely granular layer. (Fixative $\mathrm{OsO}_{4} ; \times 80,000$.)

\section{Plate 5}

Fig. 10. Part of the papillar region in a young chilled sporangium. In addition to the vesiculated layer $\left(w_{2}\right)$, a third innermost layer $\left(w_{3}\right)$ is detectable. (Fixative $\mathrm{KMnO}_{4}, \times 30,000$.)

Fig. 11. The wall of a chilled sporangium at an advanced stage of indirect germination. The three layers are clearly distinguishable with the vesicular layer $\left(w_{2}\right)$ forming a wide and discrete region between the other two layers; the third and innermost layer $\left(w_{3}\right)$ is particularly prominent. (Fixative $\mathrm{KMnO}_{4} ; \times 30,000$.)

Fig. 12. The papilla of a chilled sporangium at an advanced stage of indirect germination. The greatly enlarged vesicular layer $\left(w_{2}\right)$ now occupies the bulk of the central region of the papilla and displaces outwards the outermost homogeneous layer $\left(w_{1}\right)$. Note the elongated cristae possessed by the mitochondria $(m)$ in this and the two preceding figures. (Fixative $\mathrm{KMnO}_{4} ; \times 22,000$.) 


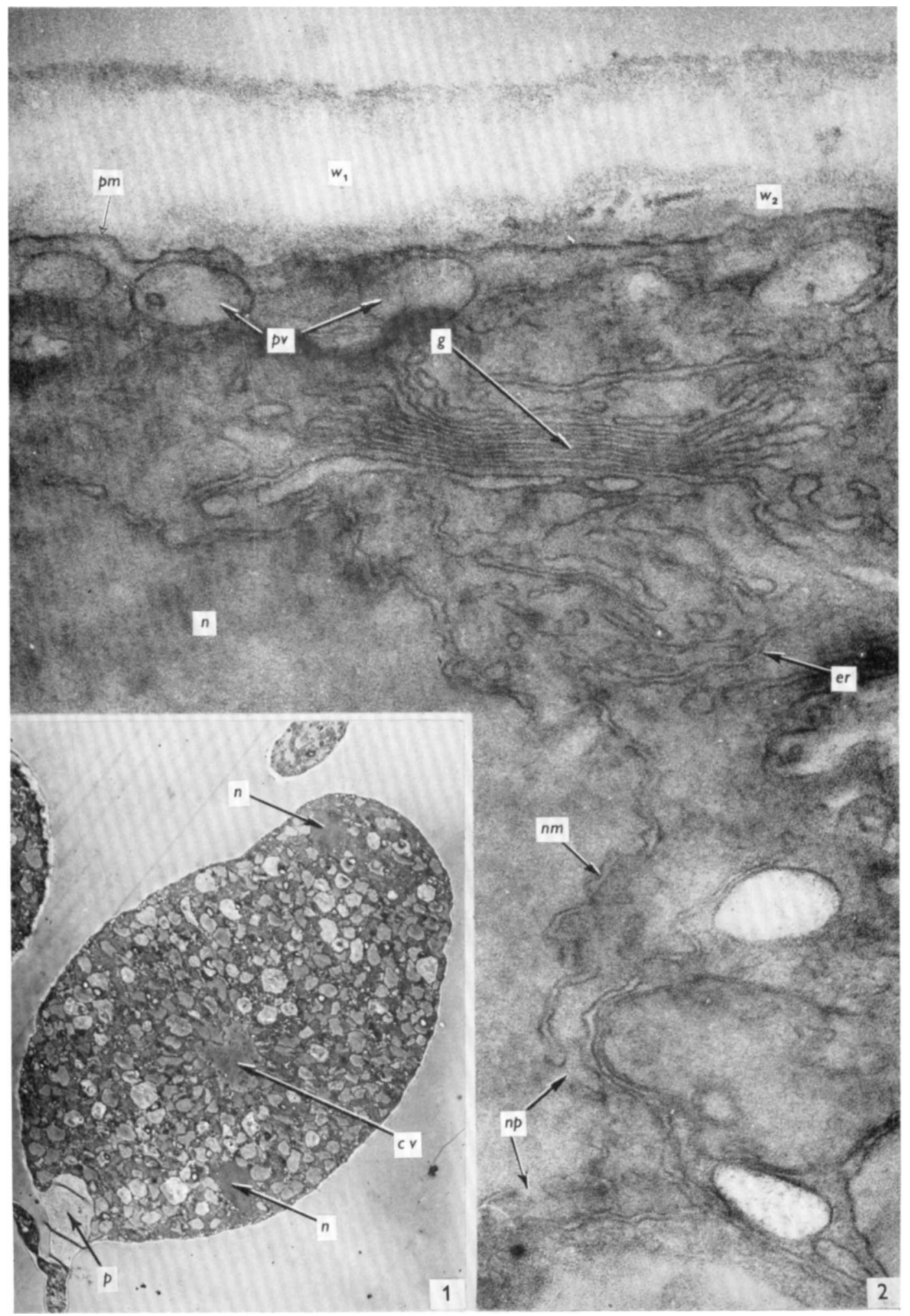


Journal of General Microbiology, Vol. 41, No. 2

Plate 2

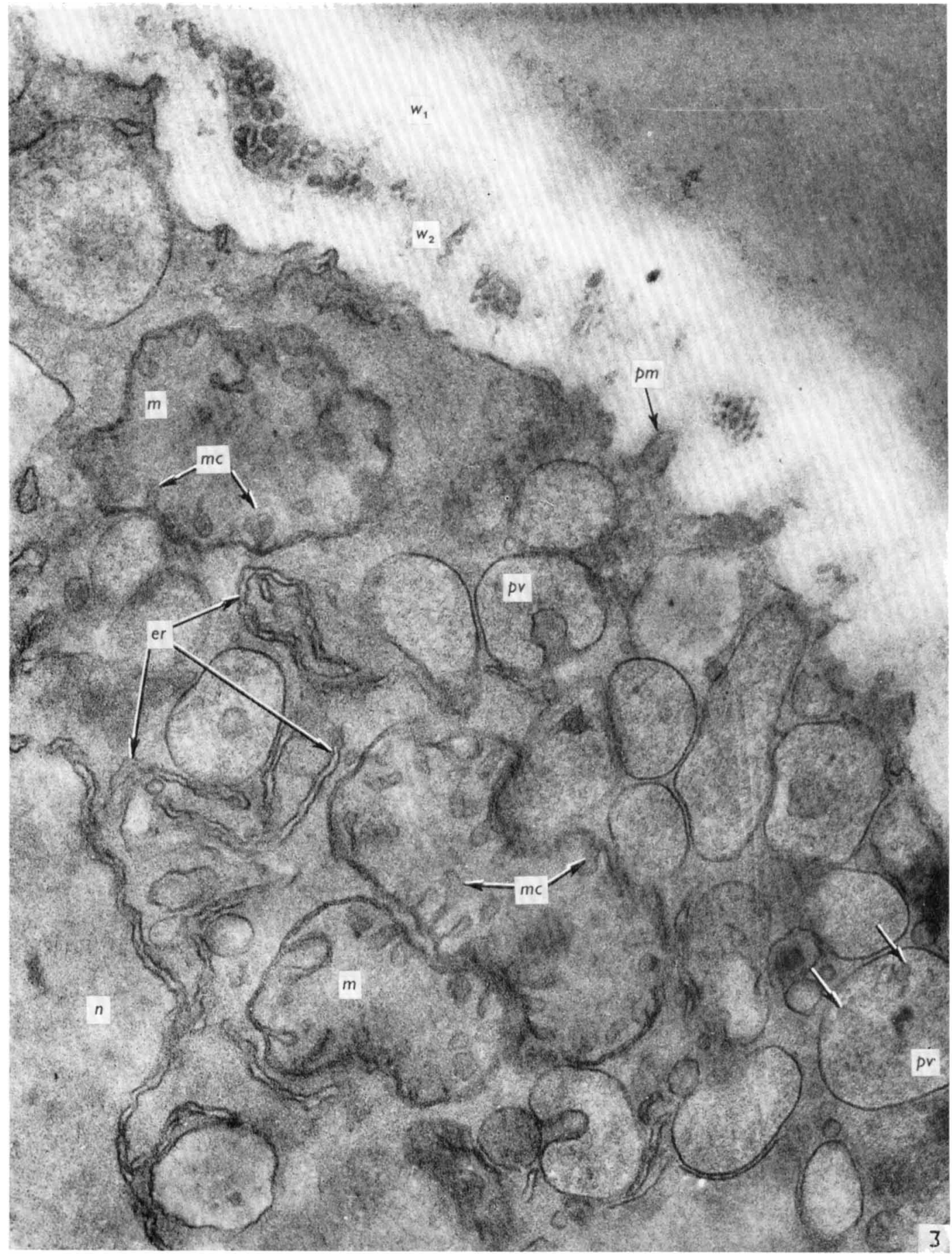

J. A. CHAPMAN AND R. VUJIČIĆ 

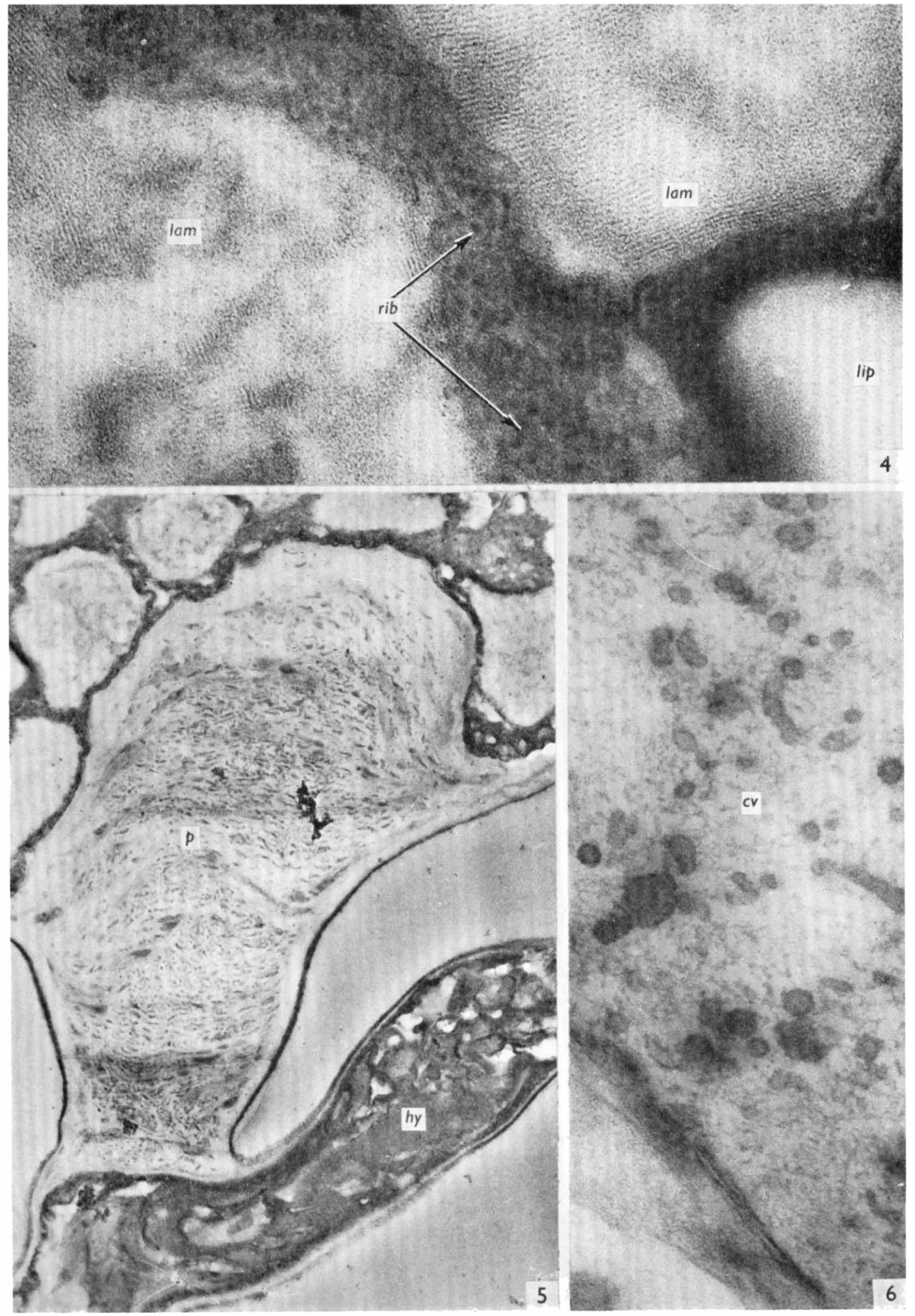

J. A. CHAPMAN AND R. VUJIČIĆ 
Journal of General Microbiology, Vol. 41, No. 2

Plate 4
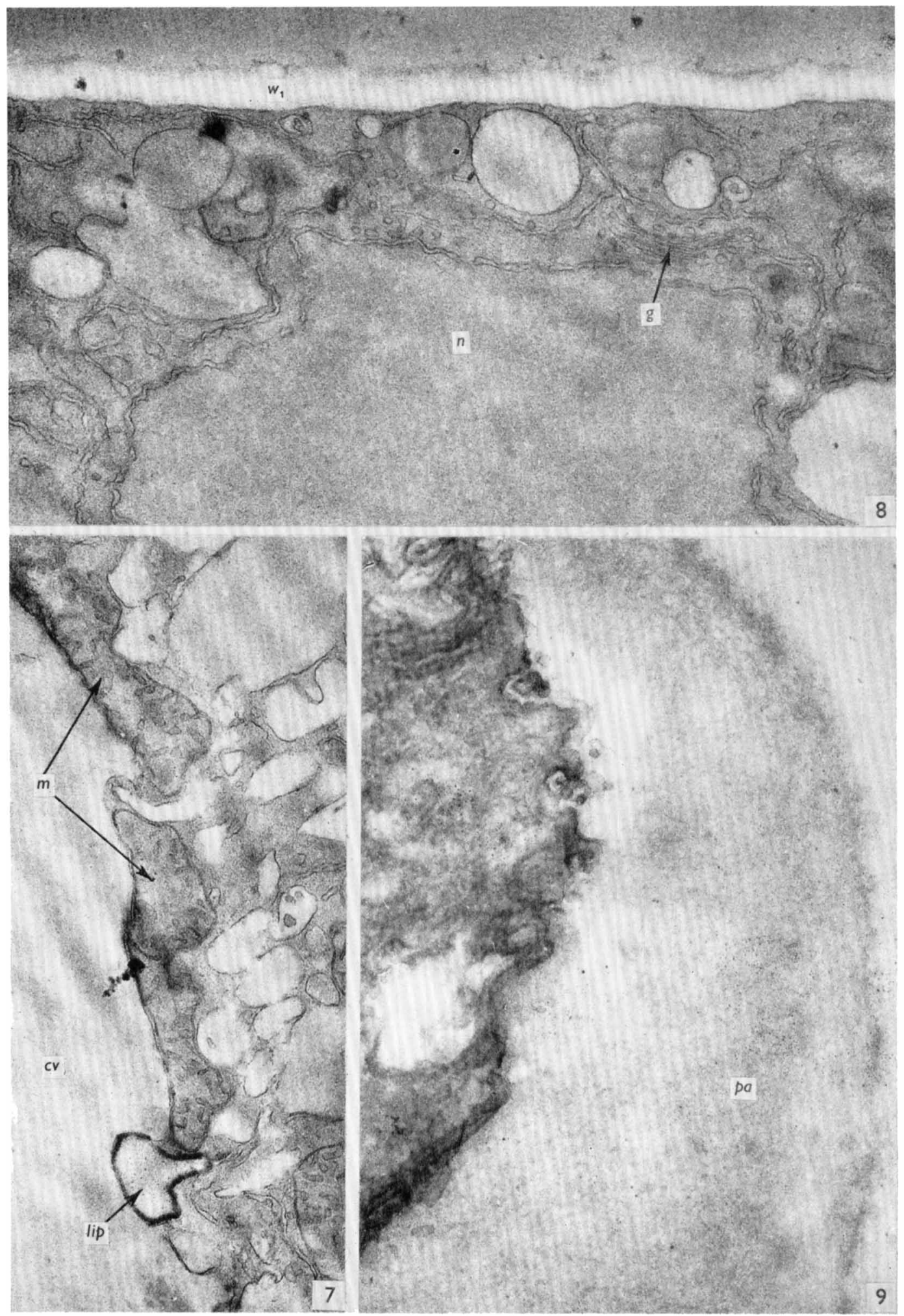

J. A. CHAPMAN AND R. VUJIČIĆ 

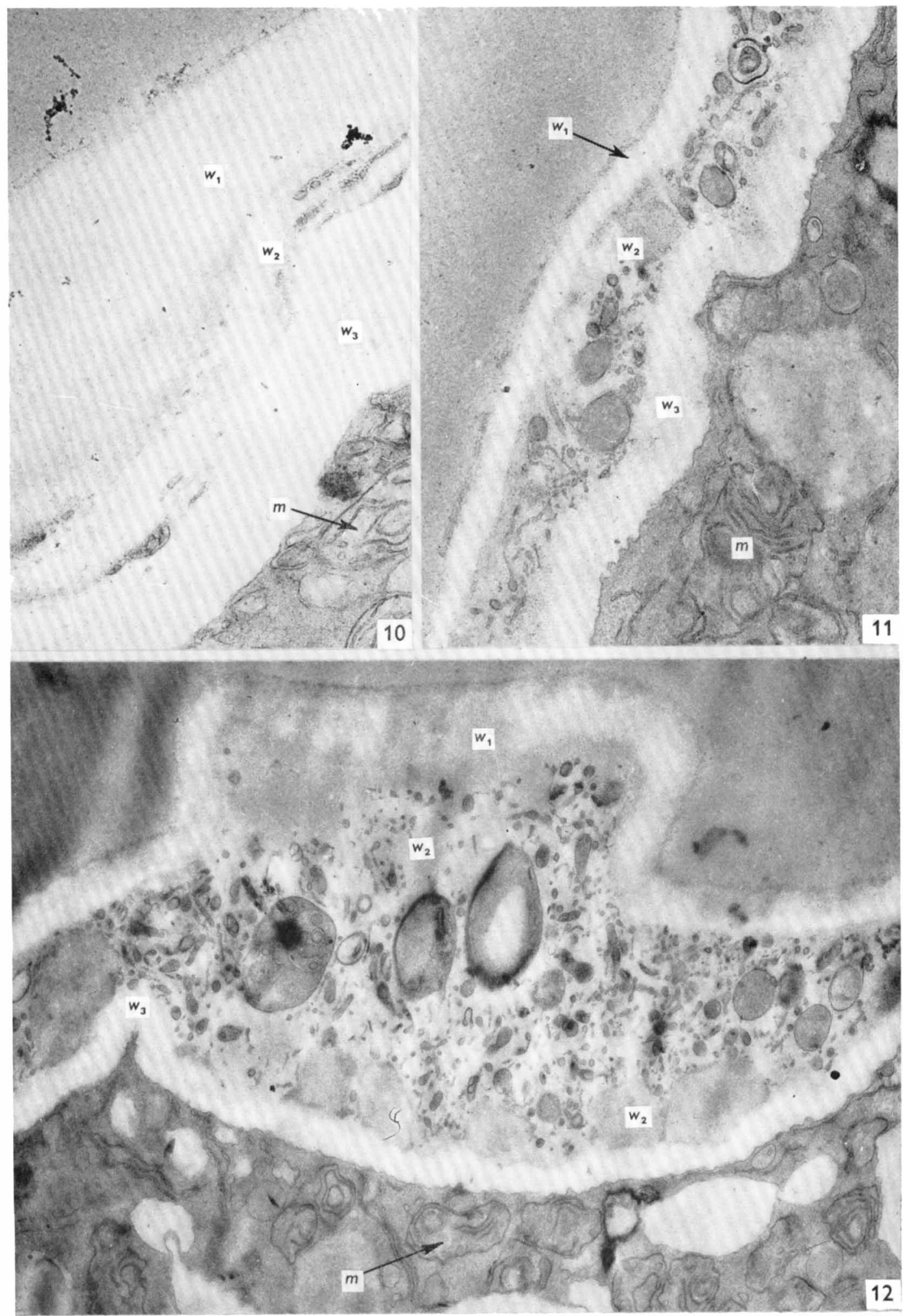

J. A. CHAPMAN aNd R. VUJIČIĆ 